\title{
Pyramidal Hologram technology in the form of a digital booklet and its impact on some defensive skills and cognitive level in handball
}

*Dr/ Ahmed Mohamed Elsayed Elkot

\section{Abstract:}

The aim of this research is to use hologram technology to support a digital booklet and to know its impact on the performance of some defensive skills and cognitive level in handball. The researcher used the experimental method using the experimental design of the pre and post measurements of two experimental groups and ,The sample included a number (44) students were withdrawn (12) students as a exploratory sample and the other of sample was divided into two groups, one experimental and the other control each of them (16) Students of the Second Division of the Faculty of Physical Education for Boys Benha University, researcher used software to design the digital booklet and the videos By Hologram, the most important results indicated differences between the two pre and post measurements of the experimental and control groups for the post measurement, and the differences between the two post measurements between the experimental and control groups for the benefit of the experimental group, and ratios The change and improvement of the skills tests and the cognitive test were higher than the group for the training of the control group and the learning using the technology of hologram achieved the highest benefit to students and is considered to be a modern technology used in the educational process

Keywords: Hologram technology, digital booklet, defensive skills, handball

\section{Introduction}

The current area is characterized by the transformation into a society dominated by modern technology and its employment

in all walks of life, and this technology has overwhelmed the different minds, which led to the fact that it is indispensable or living without

"Assistant Professor in Department of Theories and Applications of Team Sports and Tennis Sports, Faculty of Physical Education, Benha University.

Assiut Journal For Sport Science Arts 
it, became an integral part of human life, so it became imperative to keep up with the changes The accident education is the one that drives us to progress and we cannot learn best without keeping up with this change and the distance from modern technologies and their applications in education.

Ehab Mohamed Fahim (2006) points out that the degree of fascination of the learner with non-traditional methods of teaching is working to attract his attention to learning, so the process of elearning is conducted with enthusiasm because of the tool that fits their abilities and try to upgrade these abilities to reach the desired level of performance.[1]

The researcher points out that it is a modern technological innovation that enhances the educational process and makes it a factor of attraction and attention is the use of the technology of the hologram type of visual presentation and integration and employ it with one of the modern tools and methods used in the educational process.
In early January 2015, this new technology began to impose itself heavily on the ground, with the Consumer Electronics Expo 2015 CES, an announcement by Intel on RealSense Technology, which offers a new, more practical and more interesting dress [2]. Visual digital books are one of the modern technologies that have imposed a new reality on the teaching and teaching methods as a result of the information revolution that we are witnessing in the current era and contains several digital pages with some drawings and images fixed and animated and with some sounds and effects Of acoustic[3].The researcher points out that a computerized digital booklet can be designed and given to the student instead of the paper book, and becomes useless if the students overlook him or may be used by some outside the educational units and others are completely overlooked, and should be used within the educational units, especially when the images enhance And formats and videos with hologram technology, this technology provides a holographic image of different 
skill modes, for example, which enhances the value of the visual digital booklet supported by hologram technology. Talal Nazim alZaheri (2014) points out that the real use of Hologram technology. Can be applied in various fields of office work the areas of application of this technology may be Hologram books, and there are real applications in the field of books in the form of stereoscopic optical Image [Hologram books] and in 2011, Media Screen introduced an integrated digital book display system In the form of stereoscopic optical books with browsing ability. Dubbed [Monkey Book], And idea [Monkey book]. Relies mainly on Hologram technology. Through the projector, digitally stored books can be rerepresented and the projector is made up of a built-in operator with a data viewer and an interactive glass platform, the display of books in the form of a logologist, and is broadcast on interactive glass surfaces that may be touch-enabled and [Retina display] technology, which Through which the book can be browsed in a similar way to the paper format and with this technology it was possible for the first time to exceed the boundaries of textual and graphic information provided by paper and digital books, to a more comprehensive concept, namely books By hologram[4]. Khalid Hammoudah, galal Kamal Salem (2008) states that there is no doubt that learning the defensive skills in handball is a daunting task for the trainer, and that it is heavy on the young psychic who excited about to deal with the ball, and it is more difficult that many of the teachers and coaches of handball are going beyond the inclinations Instead of trying to raise their interests to learn defensive skills, which is reflected on those who are young [5]. Through the researcher's observation of the curriculum of the students of the Second Division of the Faculty of Physical Education of Benha University, where the student teaches throughout the classroom the defensive part of handball, and usually sneaks them the frustration and boredom and often think of them that the performance of defensive skills is not from $\mathrm{E}$ 
only benefit is physical pressure because of the repeated performance of defensive skills always around the $6 \mathrm{~m}$ goal circle, and the lack of a tool like the ball is a formidable offensive skills and lack of willingness to perform such skills that the researcher resorted to in the search for a non-traditional electronic learning method of thinking about the demand August to perform defensive skills and be more efficient and costeffective, namely, the use of hologram technology in the form of a visual digital booklet, where none of the studies in the sports field have touched on the use of biotechnology technology in education.

Aim: This research aims to use pyramidal hologram technology in the form of a digital booklet as an educational tool to improve the performance of some defensive skills and cognitive level in handball.

\section{Research Hypotheses}

1. There are statistically significant differences between the averages of the pre and post measurements of the control group in favour of post measurement in the performance level of defensive skills and the level of knowledge in handball

2. There are statistically significant differences between the averages of the pre and post measurements of the experimental group in favour of post measurement in the performance level of defensive skills and the level of knowledge in handball.

3. There are statistically significant differences between the averages of the post measurements between the experimental and the control groups in favor of the post measurement of the experimental group in the performance level of defensive skills and the level of knowledge in handball.

\section{Research procedures:-}

Research Methodology: The researcher uses the experimental method using the experimental design of the pre and post measurement to two groups one of them experimental and the other is control group.

Sample : The research community was chosen from the students of the 2nd Division of the Faculty of Physical Education, Benha 
University, the researcher selected a random sample of the research community (32) students, divided into two groups one experimental and

\section{Table (1)}

Mean, standard deviation, and skewness Of the research sample

\begin{tabular}{|c|c|c|c|c|c|c|c|}
\hline \multicolumn{3}{|c|}{ variables } & $\begin{array}{l}\text { Test } \\
\text { unit }\end{array}$ & Mean & SD & Median & Skewness \\
\hline \multirow{3}{*}{\multicolumn{2}{|c|}{ Growth variables }} & Age & Year & $r \cdot . \cdot r$ & $.0 Y$ & r. &.$\vee 10_{-}$ \\
\hline & & Length & $\mathrm{Cm}$ & $|V| r$ & $1 . \wedge 1$ & $1 V 1.0$ & $\because .0 \Lambda_{-}$ \\
\hline & & Weight & $\mathrm{kg}$ & 71.94 & $r .71$ & 79.0 &. $.70 Y_{-}$ \\
\hline \multicolumn{3}{|l|}{ IQ } & Deg & $r \leqslant . V$. & T.MV & ro &..$T V T$ \\
\hline \multirow{7}{*}{ 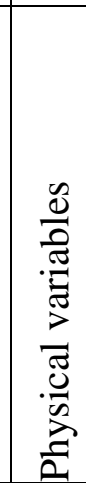 } & Transition Speed & & $\mathrm{Sec}$ & $7 . \varepsilon$ & $\cdot .17$ & 0.97 & $\because \cdot \leqslant V$ \\
\hline & $\begin{array}{l}\text { The characteristic } \\
\text { power of speed } \\
\text { for legs }\end{array}$ & & $\mathrm{cm}$ & 01.17 & $r . v 1$ & or & . ror_ \\
\hline & Flexibility & & $\mathrm{cm}$ & $\wedge . r \leq$ & 1.71 & 1.0 & $. .791-$ \\
\hline & Compatibility & & $\mathrm{Sec}$ & $V .0 \leq$ & $\cdot . \Omega \wedge$ & V.7T & •.ミ17_ \\
\hline & Agility & & $\mathrm{Sec}$ & $r 7 . \cdot A$ & 1.17 & Yo.91 & $\cdot r V T$ \\
\hline & $\begin{array}{l}\text { Endurance of } \\
\text { speed }\end{array}$ & & $\mathrm{Sec}$ & $10 . \leqslant V$ & $1.1 \mathrm{~V}$ & 10. $\leqslant V$ & 1.19 \\
\hline & Response speed & & $\mathrm{Sec}$ & 1.90 & $\because \vee V \varepsilon$ & 1.91 & Y.17. \\
\hline \multirow{5}{*}{ 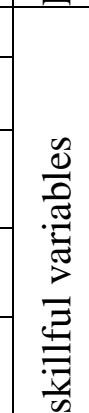 } & \multicolumn{2}{|l|}{ One-way block } & num & Y.OY & $\because 0$ & $r$ & $\because .9 \varepsilon_{-}$ \\
\hline & \multicolumn{2}{|c|}{ Two-ways block } & num & $\varepsilon .71$ & $\cdot .9 r$ & o & $\because \cdot r_{-}$ \\
\hline & \multicolumn{2}{|c|}{$\begin{array}{l}\text { Detensive moves } \\
\text { forward and backward }\end{array}$} & $\mathrm{Sec}$ & r৭.^. & 1.11 & Yq. $7 \varepsilon$ & $.0 Y_{1}$ \\
\hline & \multicolumn{2}{|c|}{$\begin{array}{l}\text { Various defensive moves } \\
\text { with direction change }\end{array}$} & Deg & Or. T & $\varepsilon .1 V$ & or & $\cdot$ rTY \\
\hline & \multicolumn{2}{|c|}{$\begin{array}{l}\text { Defensive moves to } \\
\text { cover Fastbreak }\end{array}$} & $\mathrm{Sec}$ & $10 . \wedge r$ & $\cdot \wedge$. & $10 . \vee \wedge$ & $\cdot \cdot 1{ }_{-}$ \\
\hline \multicolumn{3}{|c|}{ Cognitive Test } & Deg & $Y \cdot . T A$ & r.vq & YI.0 & $\because 0 . V_{-}$ \\
\hline
\end{tabular}

Table (1) shows that skewness of the research the other is control ,each group (16) students in addition To 12 students as an exploratory sample.

homogeneity of the sample: 
indicates the homogeneity of the sample In both physical and skill variables and cognitive level.

Data collection tools and equipment

(Restamieter /medical balance/stopwatch/measuring tape/computer/optical projector/ reflective glass prism).

\section{reference survey :}

The researcher

conducted a reference survey of various studies and references (6), (7), (8), (9), (10), (11), (12), (13), (14), (15), (16) to Identify the physical qualities and the most contributing to the defensive skills used in the research and Identification of the most frequently used defensive skills tests in question.

\section{Tests :}

- Tests of growth variables: Attach (1) - IQ test : Attach (2) Physical fitness tests:Attach (3) - offense Skill Tests :Attach (4) - Cognitive test [17]: Attach (5) validity and stability of physical tests, skills and cognitive testing: Attach (6)

- Design of digital visual booklet supported by Hologram Technology:-
Through the experience of the researcher in the programmatic field and his enrollment for several years in the programming academies to study the integrated program for the engineering industry, it was necessary to identify the programs used in the manufacture of the visual booklet, namely:

-Visual Studio 2015: [18]

-Drill Book: [19]

-Kotobeeauthor:.

-After Effect: [21]

The researcher looked at the various books and references and the international information network of the defensive incision in handball to assemble both the images and the fixed and animated formats and video files of the correct technical performance of the performance of defensive skills (in research) as well as the design Several images, forms and other video files inspired by the proper technical performance of defensive skills, to be processed before they are included in the digital visual booklet, and the process consisted of two phases:

First: Modify the different backgrounds of 
images and different shapes to opaque backgrounds as the technique is characterized by the stereoscopic display of the person leading to the skill only without the appearance of the background.

Second: It converts both images, different shapes and different videos into files that work in four directions on the projector's glass prism.

The researcher grouped each of these files according to each skill, configuration, and defensive method to link them to each other with the digital visual booklet using the Kotobeeauthor program and convert it to work on the projector, until it became operational and operational.

Attach (7) illustrates examples of the digital booklet supported by hologram technology.

\section{-Display device with Hologram technology: -}

Due to the high cost of laser projectors used in the hologram technology, the researcher used the pyramid type of it for its low cost and performance for the same purpose of the hologram stereoscopic projector, where the researcher used a 52-inch display screen, a light reflective glass prism, a projector for light, and a holder Wooden and the following figure illustrates the shape of the projector.

\section{Pre measurements :}

The researcher performed measurements experimental and control groups to ascertain the homogeneity of the two groups and this is illustrated by (Attach 8)

\section{Basic study :}

The researcher conducted the basic experiment on the Experimental research sample from $14 / 10 / 2017$ to $22 / 11 / 2017$ for a period of (6) weeks by the number of (2) weekly educational unit, with 90 minutes for the educational unit, and included the educational program on the first two parts (cognitive) of the theoretical aspect of the methods of performance Defensive skills as well as different methods and formations of defense and the other (skillful) for defensive skill performance using the Visual digital booklet supported by the hologram technology, and used the traditional method (verbal 
explanation and the performance of the model) of the control group, and attach (9) model illustrates For an educational unit of the control group, while the experimental group used the educational program using hologram technology and illustrates the attach (10) modules of the experimental group.

Statistics :-

-Percentage/average/standard deviation / median / skewness /T.Test / Person correlation coefficient

Results and Discussion

\section{Table(2)}

The difference between the two pre and post measurements to the control group In defensive skills tests and cognitive testing $\mathrm{N}=16$

\begin{tabular}{|c|c|c|c|c|c|c|c|}
\hline \multirow{2}{*}{\multicolumn{2}{|c|}{$\begin{array}{c}\text { Defensive skill } \\
\text { Tests } \\
\text { And cognitive } \\
\end{array}$}} & \multicolumn{2}{|c|}{ Pre-Test } & \multicolumn{2}{|c|}{ Post Test } & \multirow{3}{*}{$\frac{\begin{array}{c}\text { Mean } \\
\text { Difference }\end{array}}{\frac{. \vee^{\circ}}{}}$} & \multirow{3}{*}{$\frac{\text { (t.Test) }}{\frac{* 0.19}{}}$} \\
\hline & & \multirow{2}{*}{$\frac{\text { Mean }}{\text { r.o. }}$} & \multirow{2}{*}{$\begin{array}{c}\text { SD } \\
.01\end{array}$} & \multirow{2}{*}{$\frac{\text { Mean }}{\text { r. ro }}$} & \multirow{2}{*}{$\frac{\text { SD }}{\ddots . \varepsilon \varepsilon}$} & & \\
\hline$\approx$ & One-way block & & & & & & \\
\hline$\stackrel{0}{\theta}$ & Two-ways block & $\{.07$ & 1.4 & 7.11 &. .11 & 1.07 & $* 0 . \leqslant Y$ \\
\hline$\frac{\pi}{\sqrt{n}}$ & $\begin{array}{l}\text { Defensive } \\
\text { moves forward } \\
\text { and backward }\end{array}$ & $r . .11$ & 1.1. & $r 7 . \leqslant \varepsilon$ & 1.17 & T.TV & $* \wedge .0 \wedge$ \\
\hline : & $\begin{array}{l}\text { Various } \\
\text { moves } \\
\text { mofensive } \\
\text { direction change }\end{array}$ & 01.71 & $\leq .1 \leq$ & or.AI & וT.7 & r.ir & $* 0.77$ \\
\hline อ & $\begin{array}{l}\text { Defensive } \\
\text { moves to cover }\end{array}$ & $17 . \cdot 1$ &.$V Y$ & $1 \leq . \Gamma$ &.$V^{\prime}$ & r. & $* 7 . \wedge 9$ \\
\hline $\mathrm{Co}$ & רitive Test & $r \cdot . \wedge I$ & r.VA & rq.1r & $1 . \varepsilon$. & A.r. & $* 1 \cdot .1$ \\
\hline
\end{tabular}

(t) Table value on $0.05,15=2.13$

It is clear from table (7) there are statistically significant differences between the pre and post measurements in favour of post measurements in defensive skill tests and cognitive testing of the control group, where the calculated value of $(t)$ is greater than its tabular value and these differences Due to the exposure of the control group to the explanation and performance of the model when learning the defensive skills, the researcher returns the results of the post measurements to the fact that the traditional method of teaching is the verbal explanation of the skill and give an idea of how performance and model work by the teacher, then Training, 
repetition and enhancement of the training process with immediate and deferred feedback, which provides an opportunity for the student to perform properly and thus has a positive impact on the provision of immediate information when learning those skills during the education unit and has also helped to increase information and knowledge For students, which in turn has improved the recollection and comprehension when measuring their cognitive level. As the same table shows, there are statistically significant differences between the mid-and upper-intermediate

\section{Table (3)}

The difference between the two pre and post measurements to the Experimental group In defensive skills tests and cognitive testing $\mathrm{N}=16$

\begin{tabular}{|c|c|c|c|c|c|c|c|}
\hline \multicolumn{2}{|c|}{ "Defensive skill Tests } & \multicolumn{2}{|c|}{ Pre-Test } & \multicolumn{2}{|c|}{ Post Test } & \multirow{2}{*}{$\begin{array}{c}\text { Mean } \\
\text { Difference }\end{array}$} & \multirow{2}{*}{ (t.Test) } \\
\hline Anc & cognitive & Mean & $\mathrm{SD}$ & Mean & $\mathrm{SD}$ & & \\
\hline \multirow{5}{*}{ 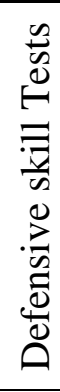 } & One-way block & r.Tr & .0 & r.07 & .01 & $.9 \varepsilon$ & $* \varepsilon . \wedge 0$ \\
\hline & Two-ways block & $\varepsilon . \wedge 1$ & .91 & 7.74 & .0 & 1.11 & *7.or \\
\hline & $\begin{array}{l}\text { Defensive moves } \\
\text { forward and backward }\end{array}$ & Y9.00 & 1.1 & ro.o. & 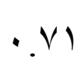 & $\varepsilon .0$ & $* 10.11$ \\
\hline & $\begin{array}{l}\text { Various defensive } \\
\text { moves with direction } \\
\text { change }\end{array}$ & or.ro & $\leqslant . \leqslant 9$ & $07 .$. & 1.0 & r.vo & $* r . \varepsilon$ \\
\hline & $\begin{array}{l}\text { Defensive moves } \\
\text { to cover Fastbreak }\end{array}$ & $10 . V V$ & $\cdot{ }^{1} 1$ & $\mid r . \wedge$ & & 1.97 & $* 1 \cdot .9$ \\
\hline \multicolumn{2}{|c|}{ Cognitive Test } & YI.VO & 1.91 & 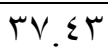 & T.IT & 10.71 & *Hr. \\
\hline
\end{tabular}

(t) Table value on $0.05,15=2.13$ 


\section{5}

Table (3) illustrate the existence of statistically significant differences between the pre and post measurements in favour of post measurements in defensive skill tests and cognitive testing of the experimental group, where the calculated value $(t)$ was greater than its tabular value, indicating The researcher that the hologram technology can be used as a tool and a modern digital method in the educational process and have been able to influence students to attract their attention without dispersion, because of the technology of the learner's entry into a realistic virtual world created by default for the student out of boredom cases The frustration of purely physical-controlled defensive exercises and the students ' attempt to imitate what they perceive to be the stereoscopic display of the technology, be they images, formats or video files, and their ability to simulate using digital technology that has also led to Improved cognitive level of the defensive side of handball. Ahmed Abdullah Al Ali (2005) confirms that the digital computerized book contains information that is available to the student and is displayed in an organized way that can be invested in educational situations, so that the student finds audio recordings and video images fixed and animated and videos, all in the context of a text containing information to help students Acquisition of experience and here these media are all integrated with each other with a system that ensures that students achieve the desired goals of education efficiently and effectively[22] . Amal alQahtani, Reem Abdallah alMoaither (2016), points out that education can be used in the field of $3 \mathrm{~d}$ technology in different ways and forms, so the physiology now offers the possibility of teaching students with the help of a virtual teacher, and this technique is characterized by the fact that the guru of biology shows Like he's in the classroom and he can see the students and talk to them, as if they were all in the same room [23]. Ghuloum, $\mathbf{H}$ (2010) illustrates the importance of using this technology in the community as a virtual assistant, and he 
can stand by you and talk to you about different topics, suggesting that this speech may seem to the reader pure fiction, but the evidence tells us to believe that it can become a reality in a few years[24].The researcher points out that this type of biology whether it is a teacher or a virtual assistant is difficult to apply in the sports field and it is difficult to link this technology with students in learning different skills for the high cost and the multitude of tools and methods used and not available as well as the need for high internet speed of Hand, on the other hand, when learning the skill part, the student needs to do the retro feed to modify and improve the performance, whether it is immediate or deferred, which invited the researcher to use the hologram quality of it.

\section{Table (4)}

The differences between the post measurements of the control and experimental groups In defensive skills tests and cognitive testing

$\mathrm{N} 1=\mathrm{N} 2=32$

\begin{tabular}{|c|c|c|c|c|c|c|c|}
\hline \multirow{2}{*}{\multicolumn{2}{|c|}{$\begin{array}{l}\text { Defensive skill Tests } \\
\text { And cognitive testing }\end{array}$}} & \multicolumn{2}{|c|}{$\begin{array}{l}\text { Control } \\
\text { group }\end{array}$} & \multicolumn{2}{|c|}{$\begin{array}{l}\text { experimental } \\
\text { group }\end{array}$} & \multirow{3}{*}{$\begin{array}{c}\begin{array}{c}\text { Mean } \\
\text { Difference }\end{array} \\
\cdot r^{\prime \prime}\end{array}$} & \multirow{3}{*}{$\frac{(\text { t. Test) }}{\frac{1 . \wedge r}{}}$} \\
\hline & & \multirow{2}{*}{$\frac{\text { Mean }}{\text { r.ro }}$} & \multirow{2}{*}{$\frac{\text { SD }}{\ddots \varepsilon \varepsilon}$} & \multirow{2}{*}{$\frac{\text { Mean }}{\text { r.07 }}$} & \multirow{2}{*}{$\frac{\text { SD }}{.01}$} & & \\
\hline \multirow{5}{*}{ 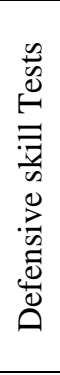 } & One-way block & & & & & & \\
\hline & Two-ways block & 7.14 & $\cdot v 1$ & 7.74 & .0 & .0 & $* Y . r \wedge$ \\
\hline & $\begin{array}{l}\text { Defensive moves } \\
\text { forward and }\end{array}$ & rт. $\varepsilon \varepsilon$ & 1.17 & ro.o. & $\cdot v 1$ & $.9 \leq$ & *Y. vo \\
\hline & $\begin{array}{l}\text { Various defensive } \\
\text { moves with direction }\end{array}$ & or.si & r.7) & $07 .$. & 1.0 & r.11 & *t.tr \\
\hline & $\begin{array}{c}\text { Defensive moves to } \\
\text { cover Fastbreak }\end{array}$ & $1 \leq . \Gamma \wedge$ & $\because v 1$ & $\mid r . \wedge 1$ & r & $.0 \mathrm{~V}$ & *Y.qu \\
\hline & Coonitive Test & rqIr & $1 \varepsilon$. & $r V \leqslant r$ & YIY & $\Delta \mu_{1}$ & $* \| r \cdot r$ \\
\hline
\end{tabular}

(t) Table value on $0.05,30=2.04$

It is clear from table (4), there are no statistically significant differences between the post measurements between the two groups on One-way

block test, as shown in the same table (4) The existence of statistically significant differences between the post measurements of the two 
groups for the experimental group in defensive skill tests and cognitive testing, where the calculated value of $(t)$ is greater than its tabular value and the researcher returns this because of the existence of a means or educational tool that works to raise the motivation of the learner towards learning on the one hand and on the other hand Because of the modernity and innovation in the use of modern technology in education, this means a different way of aligning students when watching the holographic part as well as other traditional student queuing, where says Amal Safar al-Qahtani, Reem Abdallah al-Mother (2016): It is a characteristic of the biology to see the body from all directions and see the depths of the holes and punctures on it, and to see a party hides the other if we look at the other part disappears, it can be photographed several holography images on one panel and do not overlap or interference[23]. The researcher points out that when comparing this with traditional teaching we find a distinct difference in the presentation of the educational material as well as excitement, passion and curiosity to the modern techniques used in the presentation of the educational material, which led to the superiority of the experimental group about the officer in learning using the means and tools And models and the use of modern technology in education . Ghuloum, H (2010) indicates that the hologram can be used as a medium to display $3 \mathrm{~d}$ models [24]. Amal Al Qahtani, Reem Abdallah al Moaither (2016), asserts that $3 \mathrm{~d}$ technology works by creating a $3 \mathrm{~d}$ image where a light source is dropped on the surface of the body and then dispersed while a second light source lights the body to create overlap between the two sources [23]. 
Table (5)

Percent-change In defensive skills tests and cognitive testing to the control and experimental groups $\mathrm{N} 1=\mathrm{N} 2=32$

\begin{tabular}{|c|c|c|c|c|c|c|c|}
\hline \multirow{2}{*}{\multicolumn{2}{|c|}{$\begin{array}{c}\text { Defensive skill } \\
\text { Tests } \\
\text { And cognitive } \\
\text { testing }\end{array}$}} & \multicolumn{2}{|c|}{$\begin{array}{l}\text { Control } \\
\text { group }\end{array}$} & \multirow{2}{*}{$\begin{array}{c}\text { ratio of } \\
\text { change } \\
\%\end{array}$} & \multicolumn{2}{|c|}{$\begin{array}{l}\text { experimental } \\
\text { group }\end{array}$} & \multirow{3}{*}{$\begin{array}{c}\begin{array}{c}\text { ratio of } \\
\text { change } \\
\%\end{array} \\
\% \text { \% .^ }\end{array}$} \\
\hline & & Pre & Post & & Pre & Post & \\
\hline \multirow{5}{*}{ 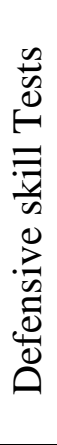 } & One-way block & Y.o. & r. ro & $\%$ & r. Tr & r.0T & \\
\hline & Two-ways block & $\varepsilon .07$ & 7.14 & $\% r \leq . r$ & $\varepsilon . \wedge 1$ & $7.7 r$ & $\%$ \% \\
\hline & $\begin{array}{c}\text { Defensive } \\
\text { moves forward } \\
\text { and backward }\end{array}$ & $r .11$ & $r\rceil . \leqslant \varepsilon$ & \% & Y9.00 & ro.o. & $\% 10 . \wedge$ \\
\hline & $\begin{array}{c}\text { Various } \\
\text { defensive moves }\end{array}$ & 01.71 & or.si & $\% \leq .1$ & OY.YO & $07 .$. & $\% \vee .1$ \\
\hline & $\begin{array}{c}\text { Defensive } \\
\text { moves to cover }\end{array}$ & 17.1 & $1 \leq . \mu$ & \%) & $10 . V V$ & $\mid r . \Lambda 1$ & $\% \backslash \leq .1$ \\
\hline \multicolumn{2}{|r|}{ Cognitive Test } & $r \cdot \Delta l$ & rq. & \% & Yl.Vo & $r V . \varepsilon r$ & $\% \vee r .9$ \\
\hline
\end{tabular}

Table (5) shows the ratio of change in the defensive skill variables of the experimental and control groups, where the ratio of change between the two measurements of the pre and post in the defensive skill tests and the cognitive test , and the ratio The largest in favor of the experimental group, these results are consistent with what was said by Amal Safar al-Oahtani. Reem Abdallah al-Mother (2016) that the technique of hologram helped to increase the joint interaction between the teacher and the learner and allow to overcome the difficulties of studying some subjects as it contributes to the acquisition of skills New teaching and help in employing modern techniques in teaching and increasing motivation for education [23]. Cho, J (2008) confirms that the technology can improve the learning process as well as other methods.[25] which was confirmed by table results (5) by the high rate of change of the experimental group that used the hologram technology to improve the performance of some defensive skills and cognitive testing in handball.

Conclusions recommendations:-

Conclusions:-

1-differences between the pre and post measurements to experimental and control groups in favor of post 
measurements in both skills tests and cognitive test.

2-There are no statistically significant differences between the two intermediate measurements between the experimental groups and the control of the one-way block test in defensive skill tests.

3. The existence of statistically significant differences between both the control and the experimental groups in the post measurements in some defensive and cognitive skills tests for the benefit of the experimental group .

4-the ratios of change and improvement of the skills tests and the cognitive test were higher in experimental group than the control.

5. Learning using hologram technology has earned the highest benefit to students and is a modern technology used in the educational process.

\section{Recommendations:-}

1. The need to use hologram technology in the educational process because of its positive impact on the learning process.

2. The need for research and research in the field of the mobile phone if one of the researchers can obtain this modern method.
3-The need to focus on the learning process to take advantage of modern and advanced technologies that serve the educational process.

4. Conduct further research into the use of virtual teacher technology by hologram.

\section{references:-}

\section{1- Ehab Mohamed Fahim} (2006): Designing a Web site and its impact on learning some field and track competitions among students of the Faculty of Physical Education in Tanta, $\mathrm{PhD}$ thesis, , Tanta University, p:3, (in Arabic)

\section{2- Nour Attieh Al-Anqawi} (2016): Teacher of the digital age, Faculty of Education, Princess Nora bint Abdul Rahman University, Saudi Arabia, p:7,(in Arabic)

3- gamal Abdulaziz AlSharhan (2003): Teaching aids and innovations in education technology, Riyadh, p:186-189 (in Arabic)

4- Talal Nazim al-Zaheri (2014): Technology applications and aspects of investment in the field of library work, Journal of Libraries, information and documentation in the Arab 
world, Issue 1, December, p:47 (in Arabic)

5- Khalid Hammouda, galal Kamal Salem (2008): Attack and defense in handball, knowledge facility, Alexandria, p:311 (in Arabic)

6- Ahmed Abdul Hameed kotb (2006): The effect of the applied training skills according to the energy production systems in the level of performance skills and physical competence of handball players, $\mathrm{PhD}$ thesis, Faculty of Sports Education, Assiut University ,(in Arabic).

7- Ashraf Fathi Abdul Mohsen (2002): Determination of physical and physiological levels as a function to develop the skill performance of handball plavers, $\mathrm{PhD}$ thesis, Faculty of Sports Education for boys, Helwan University, Cairo,(in Arabic).

8- Fathi Ahmed Hadi (2010): Modern scientific training in handball, Horus International Foundation, Alexandria.(in Arabic).

9- Sami Mohammed Ali (1999): defense in Handball, Book Centre for Publishing. ,(in Arabic).

10- Kamal Darwish, Kadri Sayed Morsi, Imad Eddin Abbas Abu Zeid (2002): Measurement, evaluation and match analysis in handball (theories- applications), Book Center for Publishing, Cairo,(in Arabic).

\section{1- Kamal Abdelhamid}

Ismail, Mohammed Subhi Hasanin (2001): Four modern handball, part one, book publishing Center, Cairo ,(in Arabic).

\section{2- Mohammed Abdulla} Abd elmordy(2013): The impact of the development of physical traits in the light of their contribution to the level of skill performance and some physiological variables of handball players, $\mathrm{PhD}$ thesis, Faculty of Physical Education for boys, Benha University,(in Arabic).

\section{3- Mohammed}

Mahmoud Marzouk (2001):

The impact of the development of aerobic and anaerobic capacity on some of the performance of defensive and offensive skills of the emerging handball, $\mathrm{PhD}$ thesis, Faculty of Physical Education for boys in Zagazig, Zagazig University,(in Arabic).

\section{4- Mustafa Ahmed} Abdulwahab (2006): The impact of a training program for the development of muscular strength on the level of skilled performance and some physical and 
physiological variables for handball players, $\mathrm{PhD}$ thesis, Faculty of Sports Education, Assiut University,(in Arabic).

15- Yahva Alaa al-Din mkld (2005): The effect of the preparation periods and competition at the level of the hormone progesterone in the blood and some physiological and physical variables of the handball plavers, $\mathrm{PhD}$ thesis, College of Physical Education, Assiut Universitv.(in Arabic).

16- Ahmed Mohamed Elkot (2015): Expert system to simulate human mind for automatic Planning of preparing period in handball , Assiut Journal Of Sports Science and Arts ,15 March . (in English)

\section{7- Ahmed Mohamed} Elkot (2016) : Virtual learning environment and its impact on skillful and cognitive learning outcomes for defensive side in handball ,European journal for sports science technology , 16 April ,p:7. (in English)

18- https://www.visualstudio .microsoft.com/vs/older(in English)

19- http://www.drillbook.net /(in English)

20- https://www.kotobeeauthor.software.informer.co m(in English)
21- https://www.adobe.com/ mena_ar/products/aftereffect s(in English)

22- Ahmed Abdullah alAli (2005): Distance education and the future of education in the Arab world, Modern book House, first edition, Cairo ,p:136,(in Arabic)

23- Amal Safar alQahtani, Reem Abdallah alMoither (2016): The awareness of the faculty members of Princess Nora University in the technique of stereotactic imaging (physiology) in distance education, Arab studies in education and psychology, issue No. 77, March,p:310,307,304,328(in Arabic)

24- Ghuloum, H(2010) :

3D Hologram Technology in learning environment ,proceeding of informing science \& IT Education Conference (insite) university of salford , Department of Built and Human Environment ,Manchester,UK Retrieved p:751,693(in English)

25- Cho,J (2008) :

Talking to Monalisa \& Michelangelo , ABC News Retrieved Jul 4 ,2015 From : http://abcnews.go.com , p:1 (in English) 